\title{
Commissural geometry and cusp fusion insights to guide bicuspid aortic valve repair
}

\author{
Jama Jahanyar, MD, PhD, Gebrine el Khoury, MD, and Laurent de Kerchove, MD, PhD
}

Video clip is available online.

Similar to the mitral valve, surgeons nowadays increasingly attempt to repair a regurgitant aortic valve due to its edge over prosthetic aortic valve replacement with better longterm survival, fewer thromboembolic events, and overall improved quality of life. ${ }^{1-6}$ This is facilitated by a better understanding of the aortic valve and its functional aortic annulus (FAA), basal ring to sinotubular junction (STJ), in addition to Gebrine el Khoury's application of Alain Carpentier's mitral valve principals to the aortic valve. ${ }^{7}$ Moreover, aortic valve repair also include bicuspid aortic valves (BAVs), but a repair-oriented classification guiding the surgical approach has been lacking.

There have been various descriptive classifications in the past, but from a surgeon's point of view, they do not aid in generating a repair strategy. ${ }^{8-11}$ These classifications are too simplistic, only focusing on patterns of cusp fusion and the presence or absence of a raphe (nonfunctional commissure). They do not capture the true 3-dimensional anatomy and variability of the BAV.

Nonetheless, our insights into valve phenotypes have evolved, and we now understand that commissural orientation $(\mathrm{CO})$ in BAVs is critical in determining the correct repair strategy, and perhaps also influences outcomes after BAV repair. ${ }^{12,13}$ Other elements, which also factor into decision making, are length of cusp fusion, height of the nonfunctional commissure (raphe), as well as quality/quantity of cusp tissues and annular dilatation. ${ }^{12-16}$

\footnotetext{
From the Department of Cardiovascular and Thoracic Surgery, Cliniques Universitaires Saint-Luc, Université Catholique de Louvain, Brussels, Belgium.

Received for publication Dec 2, 2020; accepted for publication Dec 2, 2020; available ahead of print Jan 29, 2021.

Address for reprints: Laurent de Kerchove, MD, PhD, Department of Cardiovascular and Thoracic Surgery, Cliniques Universitaires Saint-Luc, Ave Hippocrate 10, 1200 Brussels, Belgium (E-mail: laurent.dekerchove@uclouvain.be).

JTCVS Techniques 2021;7:83-92

2666-2507

Copyright (C) 2021 The Authors. Published by Elsevier Inc. on behalf of The American Association for Thoracic Surgery. This is an open access article under the CC BY-NCND license (http://creativecommons.org/licenses/by-nc-nd/4.0/).

https://doi.org/10.1016/j.xjtc.2020.12.043
}

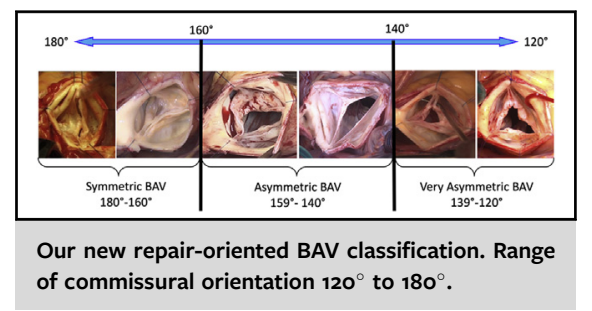

CENTRAL MESSAGE

We present our new repairoriented BAV classification, which better describes the complex 3-dimensional geometry/anatomy of BAV and aims at facilitating surgical repair. See Commentaries on pages 93 and 95 .

\section{ANATOMIC CONSIDERATIONS}

In a recent study analyzing BAV anatomy in a large cohort of patients who underwent valve preservation and repair, we observed that BAV phenotypes follow a continuous spectrum, with the $\mathrm{CO}$ and thus angulation of leaflet coaptation area, ranging from $120^{\circ}$ to $180^{\circ}$ (Figure 1$)^{13}$ For the purpose of repair, we divide this wide spectrum into 3 different phenotypes (Table 1). The most symmetric valves range from $160^{\circ}$ to $180^{\circ}$, asymmetric valves from $140^{\circ}$ to $159^{\circ}$, and very asymmetric valves from $120^{\circ}$ to $139^{\circ}$ (Figure 2). The pattern of cusp fusion (right/left in $83 \%$, right $/$ non in $15 \%$, and non/left in $2 \%$ ) was similarly distributed amongst the 3 phenotype groups. Aortic dilatation $(\geq 45 \mathrm{~mm})$ was present in $47 \%$ of symmetric, $37 \%$ of asymmetric, and $39 \%$ of very asymmetric phenotypes.

The aortic annulus in BAV tends to be larger than in trileaflet aortic valves (TAVs), especially in BAV with aortic regurgitation (AR), where it reaches a diameter of $30 \mathrm{~mm}$ on average. ${ }^{17,18}$ Here, it is important to note that the cause of annular dilatation in BAV is mainly secondary to dilation of the anterior septal and thus muscular portion of the ventriculo-aortic junction (VAJ), rather than the posterior fibrous portion of the VAJ.

The nonfused cusp in BAV, generally has a higher geometric height compared with the fused cusps, and hence carries most of the available leaflet tissues. ${ }^{13,19}$ Moreover, 


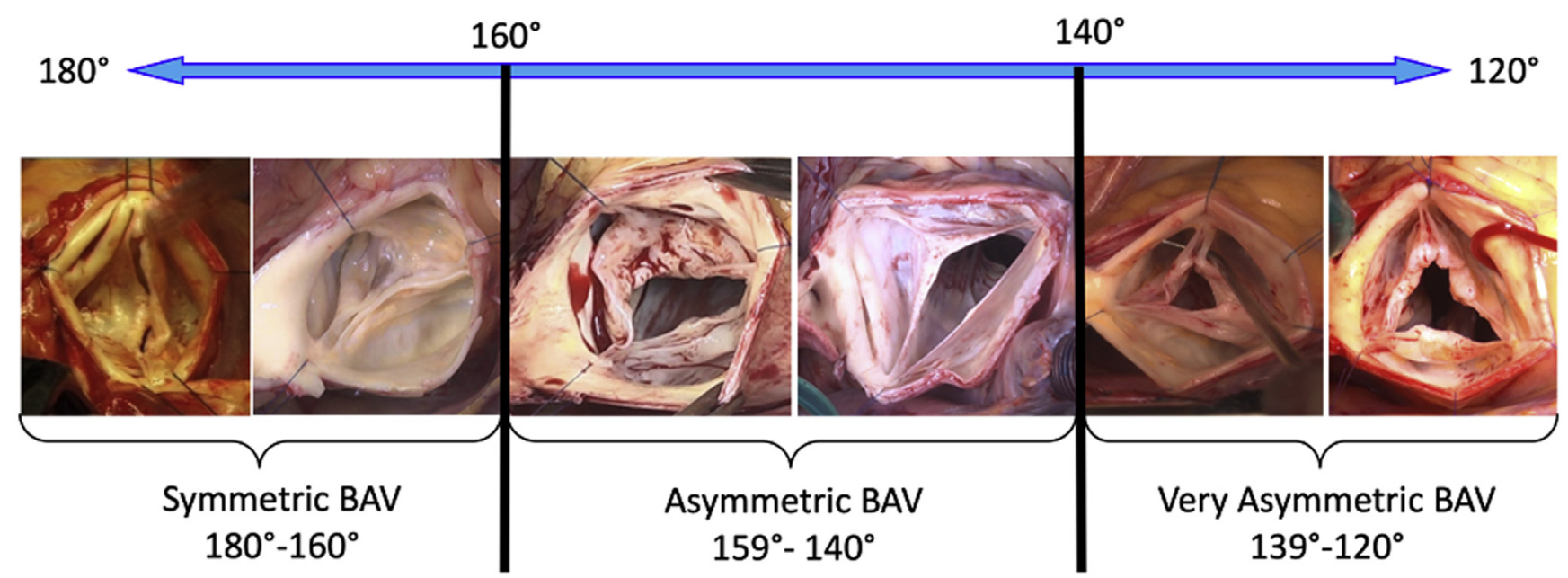

FIGURE 1. Our new repair-oriented BAV classification. Range of commissural orientation $120^{\circ}$ to $180^{\circ}$. $B A V$, Bicuspid aortic valve.

it also tends to be the most pliable and mobile, and thus least restrictive cusp in BAV. Accordingly, during repair the nonfused cusp can be utilized to cover more of the aortic orifice if the fused cusp is small, in analogy to the anterior leaflet during mitral valve repair.

The cause of regurgitation tends to be the same in all 3 phenotypes. There always appears to be a prolapse of the fused cusps, which in general is more pronounced in the right component of the fused cusp, in asymmetric and very asymmetric phenotypes (in right/left-fusion).

A bileaflet prolapse can also occur and is mostly prevalent in the symmetric phenotype. The geometric height of cusps in the symmetric phenotype is also larger, and thereby provides more favorable leaflet tissues for valve repair.

Thus, in BAV with AR the mechanism for regurgitation is almost always a prolapse of the fused cusp, with varying degrees of fibrous and calcific degeneration, and an associated annulus dilatation. The nonfused cusps are generally normal and are rarely prolapsing, except in symmetric $\mathrm{BAV}$, or after valve-sparing root replacement for root aneurysm, hence iatrogenic.
Via pre- and intraoperative echocardiography, general parameters are established, such as the diameters of the aortic annulus, sinus of Valsalva, STJ, and ascending aorta, as well as the $\mathrm{CO}$. The $\mathrm{CO}$ is the angle measured on the sides of the nonfused cusp between 2 lines joining the central axis of the aortic root and the commissures (Figures 3 and 4). In clinical practice, the CO is measured on transesophageal short axis view in diastole. ${ }^{20}$

Intraoperatively, the surgeon determines the pattern of cusp fusion (right/left, right/non, and non/left), geometric height of the cusps, and length of raphe fusion. In TAVs, the height of commissures is found to be equal, whereas in true bicuspid valves (Sievers 0), the height of the nonfunctional commissure (the raphe) is zero. Across the spectrum of BAV phenotypes, the height of the raphe varies, but always appears lower than the height of the functional commissures, except in BAV fruste (Table 1). ${ }^{13,21}$

With increasing asymmetry of the $\mathrm{CO}$, an increased height of the raphe and a shorter line of fusion between cusps is observed. Hence, in symmetric BAVs we observe the opposite, with a longer line of fusion between cusps

TABLE 1. BAV phenotypes, anatomy, pathophysiology, and surgical approach

\begin{tabular}{|c|c|c|c|c|c|}
\hline BAV phenotype & $\begin{array}{c}\text { Commissural } \\
\text { orientation }\end{array}$ & $\begin{array}{l}\text { Raphe } \\
\text { height }\end{array}$ & Cusp fusion & Prolapse & Repair \\
\hline True symmetric & $180^{\circ}$ & None & Complete & $\begin{array}{l}\text { None*, } 1 \text {, } \\
\text { or } 2 \text { cusps }\end{array}$ & Cusp plication(s), $180^{\circ}$ repair \\
\hline Symmetric & $160^{\circ}-180^{\circ}$ & Close to BR & Long fusion & Fused cusp & Cusp plication, $180^{\circ}$ repair \\
\hline Asymmetric & $140^{\circ}-159^{\circ}$ & Below STJ & Short fusion & Fused cusp & Raphe thinning, direct raphe closure, $180^{\circ}$ repair \\
\hline Very asymmetric & $120^{\circ}-139^{\circ}$ & Close to STJ & $\begin{array}{l}\text { Very short } \\
\text { fusion }\end{array}$ & Fused cusp & Tailored approach \\
\hline Fruste & $120^{\circ}-139^{\circ}$ & At STJ & $\begin{array}{l}\text { Very short } \\
\text { fusion }\end{array}$ & Fused cusp & $\begin{array}{l}\text { Commissurotomy, commissure resuspension, } \\
\text { commissure reconstruction with patch }\end{array}$ \\
\hline $\begin{array}{l}\text { Fenestrated/ } \\
\text { Chordal raphe }\end{array}$ & $120^{\circ}-139^{\circ}$ & $\begin{array}{l}\text { Close to or } \\
\text { at STJ }\end{array}$ & Short fusion & Fused cusp & Cord resection, direct raphe closure, $180^{\circ}$ repair \\
\hline
\end{tabular}

$B A V$, Bicuspid aortic valve; $B R$, basal ring; $S T J$, sinotubular junction. *In case of root aneurysm without AR, the valve phenotype is generally a true BAV. 


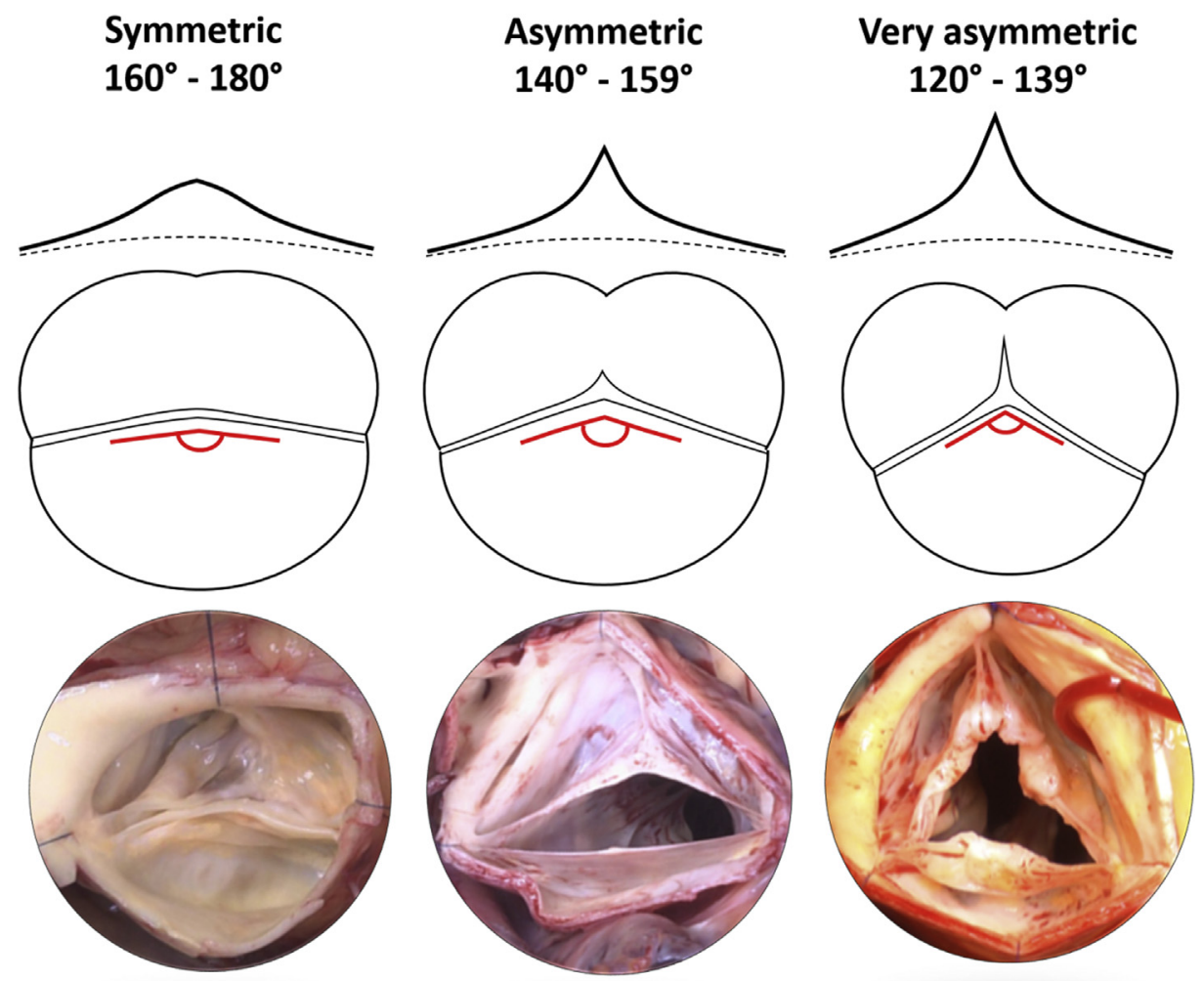

FIGURE 2. Repair-oriented classification of bicuspid aortic valve (BAV) phenotypes. Upper panel, Raphe height. Middle panel, Respective commissural orientation and raphe fusion. Lower panel, Surgical view of native valve.

and a lower raphe closer to the nadir of the fused cusp. ${ }^{13}$ These detailed differences are important and will dictate our tailored surgical approach.

\section{SURGICAL TECHNIQUES}

The main objectives for repairing a regurgitant BAV are thus, to correct a fused cusp prolapse (while preserving its mobility) and to stabilize the repair. Although central cusp plication can easily and effectively treat a prolapse in symmetric BAV, this technique of central plication and direct closure cannot be utilized in asymmetric phenotypes without rendering the cusp immobile and placing the plication suture at risk for dehiscence. Patch augmentation is also not a durable option to treat a fused cusp prolapse in asymmetric BAV. ${ }^{12,22}$ To overcome the lack of tissues in asymmetric BAV, valve symmetrization is therefore the best option. Effectively placing the commissures at $180^{\circ}$ in asymmetric BAV proportionally decreases the surface area of the aortic valve orifice covered by the fused cusp, and in turn increases the area covered by the more mobile nonfused cusp. The amount of fused cusp tissue will then become sufficient to perform central plication or direct closure and preserve cusp mobility with less tension on the sutures.
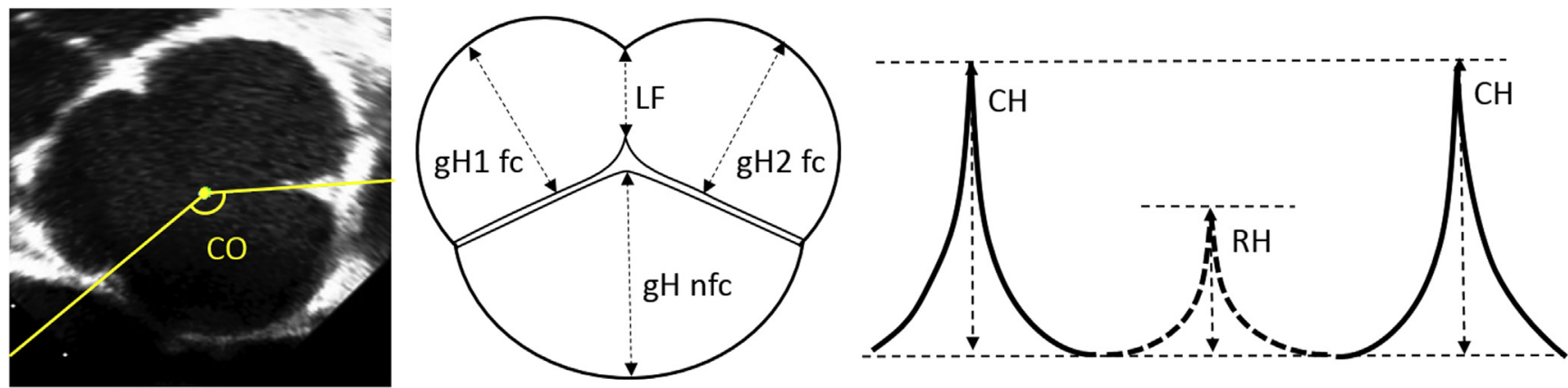

FIGURE 3. Illustration of measurements of interest in bicuspid aortic valve (BAV) repair. Transesophageal echocardiographic assessment of commissural orientation $(C O)$. Intraoperative measure of geometric height $(g H)$ of fused cups $(f c)$ and nonfused cusp $(n f c)$ and length of cusp fusion line $(L F)$; height of raphe $(\mathrm{RH})$ and commissures $(\mathrm{CH})$ in BAV. 

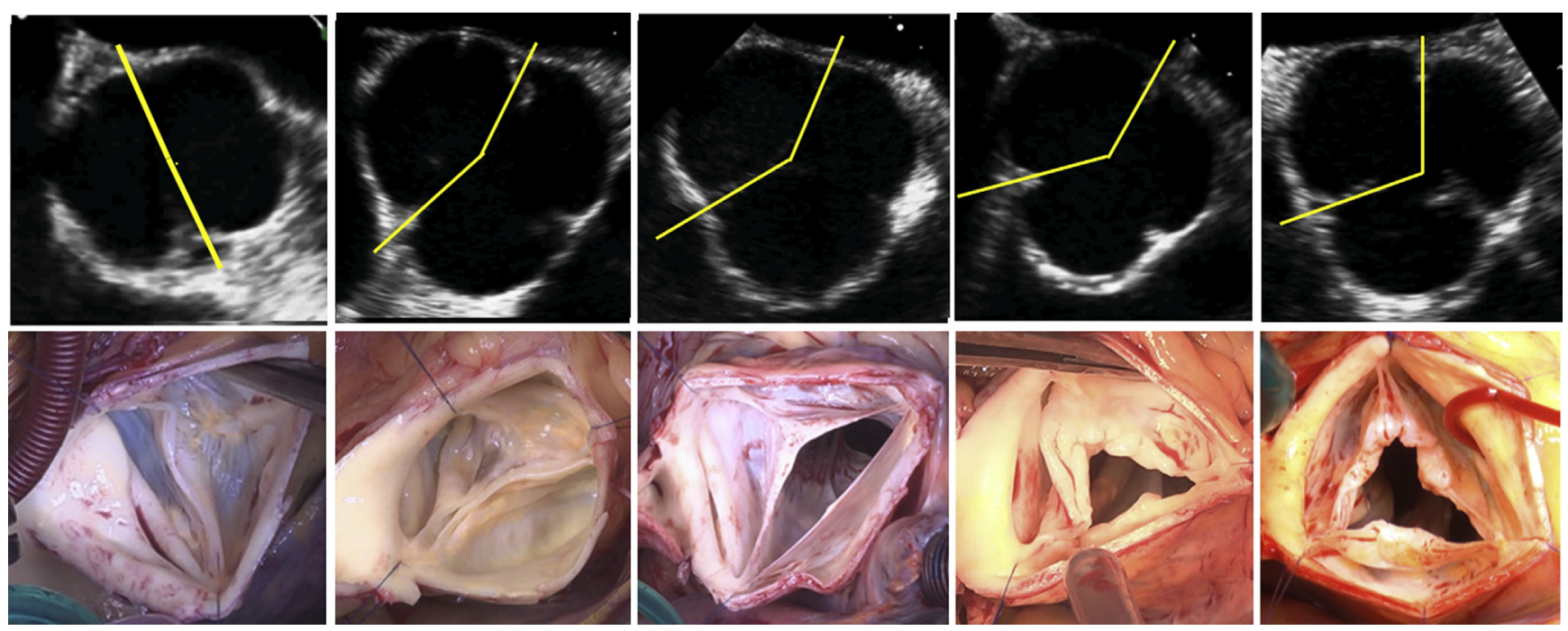

FIGURE 4. Upper panel, transesophageal echocardiography assessment of commissural orientation on short axis in diastole; view from underneath the valve. Lower panel, Respective surgical view from above the valve.

Moreover, the reduction of the annulus and root size with annuloplasty and root replacement will further help to take off tension on the central plication suture of the fused cusp.

During the past 2 decades several techniques were developed or modified to repair a BAV, following the general principles described above. BAV symmetrization has been performed utilizing sinus plication techniques and valve-sparing reimplantation or remodeling procedures. $^{23,24}$ After realization that a large aortic annulus was a predictor of repair failure, and that the Cabrol annuloplasty was inadequate to stabilize a BAV repair, ${ }^{25,26}$ several circumferential annuloplasty techniques were devised, such as the external ring, the suture annuloplasty, and the reimplantation technique. These techniques were instrumental in achieving long term stability of BAV repairs. ${ }^{16,25,27}$ Both the external ring annuloplasty and reimplantation technique require deep external root dissection (Figure 5) separating the left and right ventricular outflow tracts (El Khoury maneuver). This allows for the ring or graft to be placed outside of the heart and at the level of the basal ring.

At our institution, we have gathered a cumulative surgical experience of more than 1000 aortic valve repairs. In particular, one-third of these cases were BAV repairs. For more than a decade now, we have increasingly utilized the reimplantation technique to repair most BAV with severe AR (with or without root dilatation). This technique, pioneered by Tirone David to treat aortic root aneurysms with normal or near normal TAV anatomy, can also accommodate a BAV with AR. It efficiently remedies all the key issues present in BAV pathology, such as the valve asymmetry, the large annulus, and the aortopathy. For the specific requirements of BAV repair, we have modified the David I reimplantation technique into what we call the $180^{\circ}$ reimplantation-El Khoury technique. ${ }^{28}$

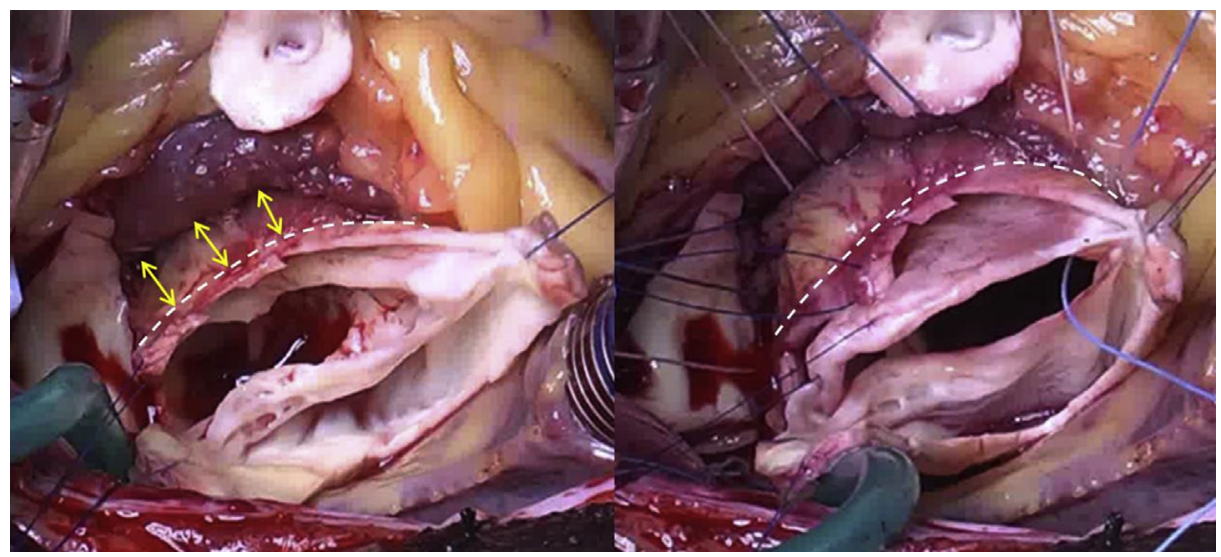

FIGURE 5. Deep root dissection below the level of the ventriculo-aortic junction (VAJ) (dotted line), with separation of right- and left-ventricular outflow tracts. Placement of annuloplasty sutures at the level of the basal ring (interventricular septum [yellow arrows]). 


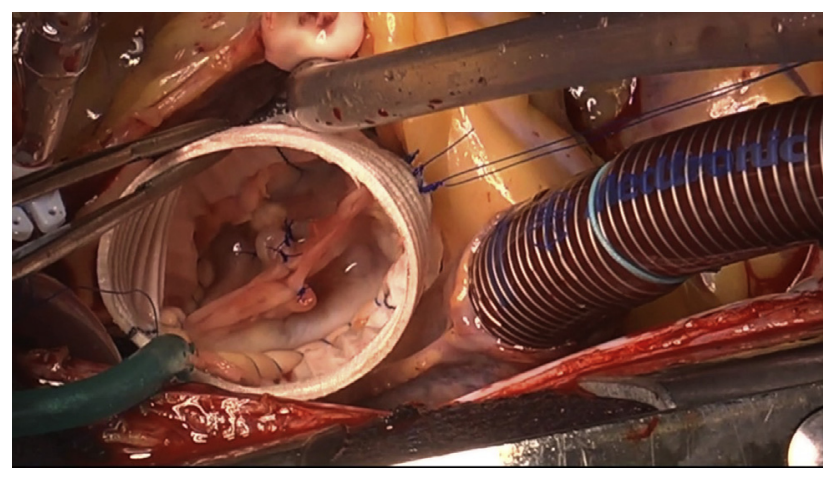

VIDEO 1. Bicuspid aortic valve repair: Symmetric phenotype. $180^{\circ}$ reimplantation technique. Video available at: https://www.jtcvs.org/article/ S2666-2507(21)00106-1/fulltext.

In the $180^{\circ}$ reimplantation technique, we transform the BAV geometry into a symmetric configuration with $\mathrm{CO}$ of $180^{\circ}$. This entails the proximal basal ring; the valve leaflets, creating symmetric free margins lengths, symmetric sinus depths, and cusp geometric height as well as equal bileaflet motion; and a symmetric STJ. Thus, remodel and stabilize the FAA at every level. This full root stabilization from VAJ to STJ, then in turn facilitates valve repair and enhances leaflet coaptation.

Our $180^{\circ}$ reimplantation technique has previously been described $^{28}$ (Video 1). Briefly, after deep external root dissection to the level of the basal ring, a tailored number of pledgeted subvalvular horizontal mattress sutures are placed circumferentially along the basal ring; except for the area around the membranous septum where the suture line follows cusp insertion to avoid conduction system injury. We typically place 1 suture at each commissure, and an additional 5 sutures under the fused cusp, and 3-4 under the nonfused cusp. The sutures are then placed through the proximal end of a Gelweave Valsalva graft
(Vascutek Ltd, Terumo Group, Renfrewshire, United Kingdom) in a fashion that allows for placement of the base of each commissure at $180^{\circ}$ (Figure 6). This also accommodates each cusp (fused and nonfused) in half of the graft's circumference, respectively. The size of the graft has been determined by measuring the length of distance between basal ring and tip of non/left commissure. The particular distribution of subvalvular sutures on the graft leads to symmetrization at the level of the VAJ, through greater compression/purse string effect of the annulus under the fused cusp compared with the annulus under the nonfused cusp. The commissures are then reimplanted at $180^{\circ}$ at the level of the neo-STJ of the graft. A correct, as high as possible, commissure resuspension also ameliorates a cusp prolapse.

The leaflets then have to be modified to achieve symmetry, which also depends on correctly implanting the commissures in the prior steps, as well as completing the line of raphe fusion and reimplanting the raphe at the level of the nadir of the fused cusp, to create equal depths of both sinuses. With asymmetric compression of the basal ring and $180^{\circ}$ commissural reimplantation, the unfused portion of the raphe can be reapproximated primarily and tensionfree, without the need for cusp augmentation with patch material. At the same time, this also ensures mobility of the fused cusp.

The STJ is intrinsically stabilized by the Valsalva graft itself. With these modifications, cusp geometry and motion are restored, and an optimal area of coaptation is achieved with stability over time.

\section{Symmetric Phenotype $160^{\circ}-180^{\circ}$}

The symmetric phenotype has the most favorable morphology, and in our experience represents $30 \%-40 \%$ of BAV with AR. The valve is already symmetric, with a

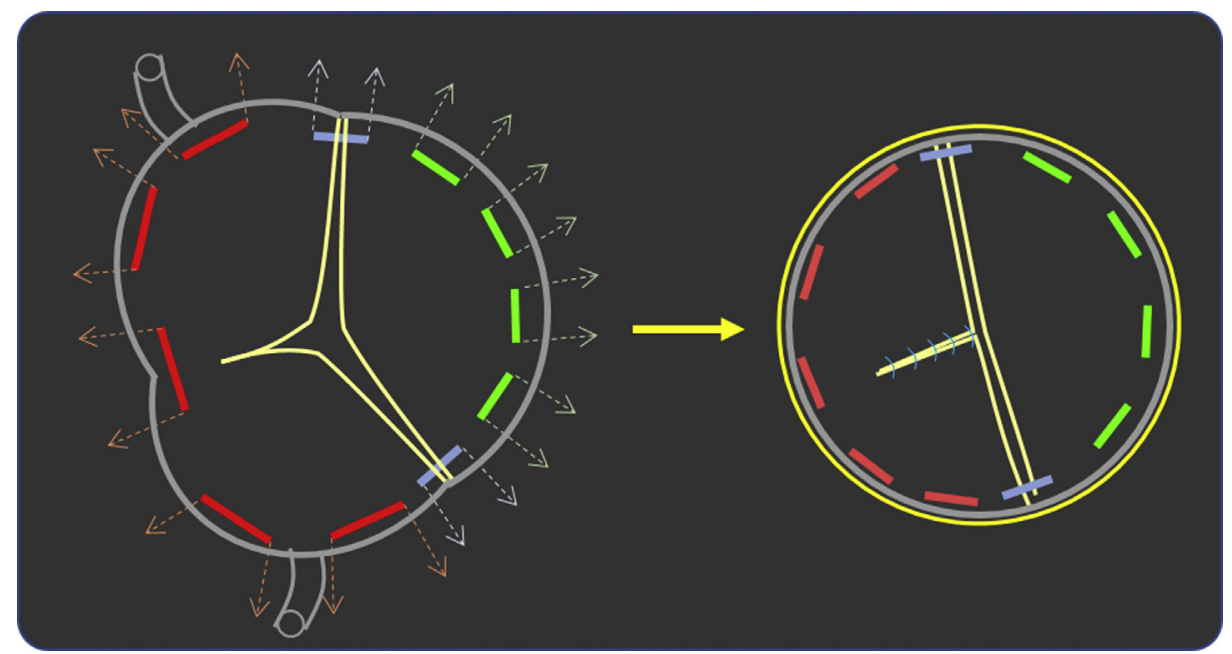

FIGURE 6. Placement of basal ring sutures in bicuspid aortic valve (BAV). Selective annuloplasty to achieve symmetry at the level of the basal ring, which also sets up correct $180^{\circ}$ placement of the commissures (Valsalva graft [yellow ring]). 
wide commissural angle. The cusps are similar in size and shape, and cusp fusion is complete or nearly complete. Moreover, the raphe inserts low on the aorta and close to the basal ring.

The main goal of the repair is to correct the fused cusp prolapse by central plication. These valves do not necessarily need commissural reorientation because their commissures are already $180^{\circ}$ or close to $180^{\circ}$. The symmetry is therefore either preserved or enhanced toward $180^{\circ}$, utilizing the aforementioned El Khoury technique (Figure 7).

\section{Asymmetric Phenotype $140^{\circ}-159^{\circ}$}

This phenotype represents $40 \%-50 \%$ of BAV with AR. As the angle of the $\mathrm{CO}$ decreases, the sinuses become increasingly disproportionate. With increasing size of the fused cusp sinuses, a decreased line of fusion and higher raphe, with a higher hinge point and insertion of the fused cusp ensues. Thus, the raphe fusion is partial and its insertion on to the aortic wall is above the basal ring but below the STJ.
However, the main repair goal is to correct the fused cusp prolapse, by direct closure of the unfused portion of the raphe. To facilitate direct closure, while still preserving cusp mobility, the valve has to be made symmetric with the $180^{\circ}$ reimplantation technique described above. In this phenotype, the raphe is detached from the aorta down to the level of cusp insertion, while paying attention not to perforate the leaflet itself. The thickened portion of the raphe often requires shaving, to improve cusp mobility at the hinge point of the raphe, where a new nadir will be created.

When the aortic remnant is sutured to the Valsalva graft with a running 4.0 Prolene suture, the raphe of the fused cusp is lowered near to the level of the basal ring, which creates a new nadir of the fused cusp. This is done to achieve a similar and symmetric height of the fused cups and nonfused cusp nadirs.

The annuloplasty and the new valve configuration of $180^{\circ}$, enhances the fused cusp mobility and once again allows for primary closure of the unfused portion of the raphe (Figure 8). This then increases the geometric height of the fused cusp and treats the prolapse by achieving
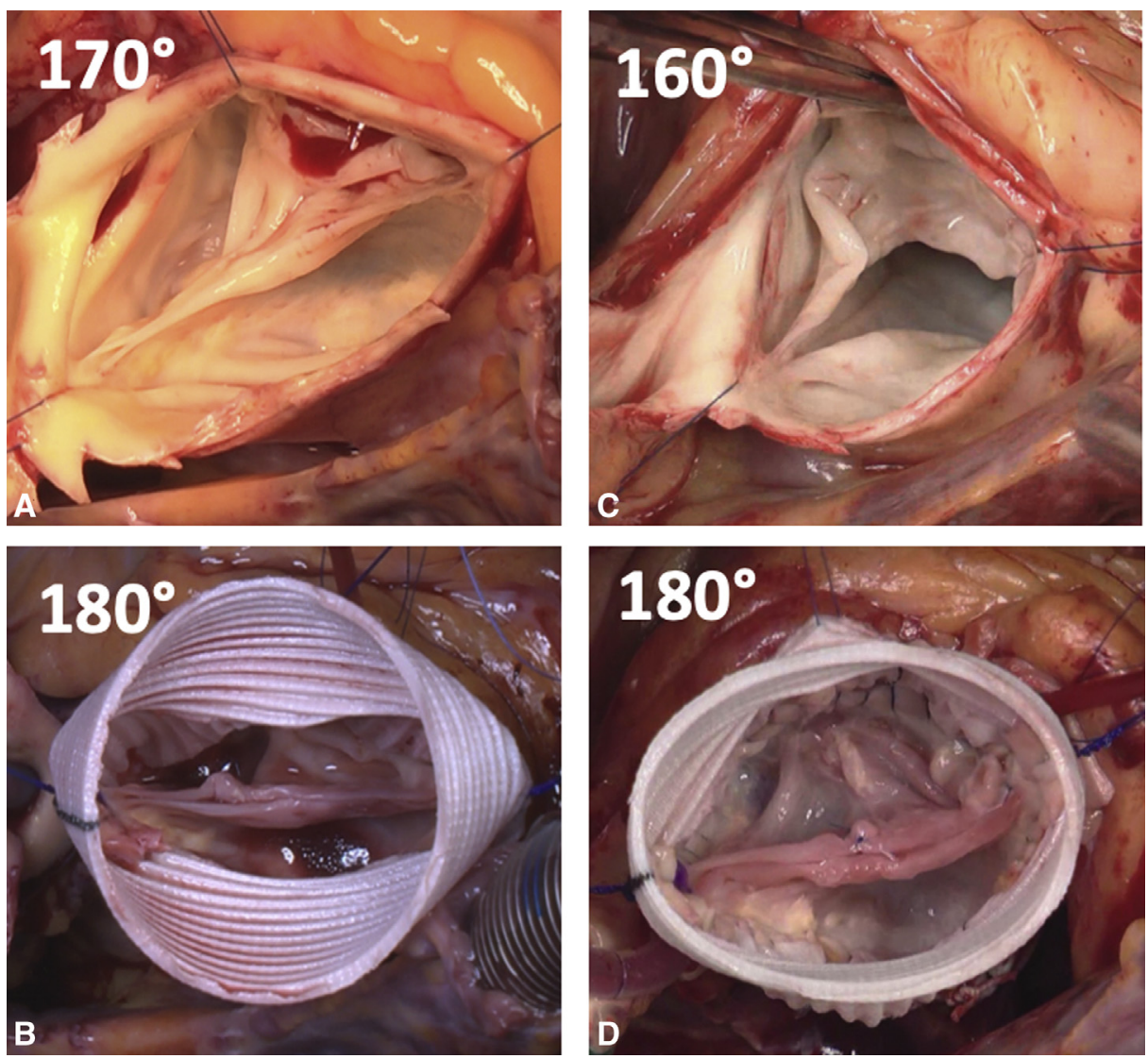

FIGURE 7. Symmetric phenotype; requires central plication with $180^{\circ}$ reimplantation technique. A and B, One hundred seventy-degree bicuspid aortic valve (BAV) repaired with $180^{\circ}$ reimplantation technique. C and D, One hundred sixty-degree BAV repaired with central plication of fused cusp and $180^{\circ}$ reimplantation technique. 
similar length of the free margins of fused and nonfused cusps, with an identical effective height of $\approx 9 \mathrm{~mm}$.

\section{Very Asymmetric Phenotype $\mathbf{1 2 0}^{\circ}-139$}

This phenotype represents $10 \%-20 \%$ of BAV with AR. The valve is very asymmetric with a narrow commissural angle. The cusps are very different in size and shape, and the raphe fusion is short and its insertion on the aortic wall is high and close to the level of the STJ. This is the most challenging anatomy, and the repair strategy depends on the morphology of the fused cusp. We distinguish 2 types: 1 type is approached in a similar fashion as the asymmetric phenotype; the other type is treated like a TAV.

The trileaflet-like BAV, also known as BAV fruste, is repaired similar to a TAV (Figure 9). These valves generally exhibit less annular dilatation and do not need modification of their geometry. Hence, we are less inclined to perform a valve reimplantation. Annuloplasty here may consists of an external ring (for severe VAJ dilatation $>26 \mathrm{~mm}$ ) or a Cabrol annuloplasty at the level of the 3 commissures (for moderate VAJ dilatation $\leq 26 \mathrm{~mm}$ ).

The fused cusp repair can also vary. If the raphe fusion is very short and reaches to the level of the STJ (BAV fruste), the treatment can just consist of commissurotomy with or without cusp shaving and possibly central plication of the prolapsing cusp (often the right coronary cusp) (Figure 9, $A$ and $B$ ). If the raphe is short but does not reach the level of the STJ, a commissure resuspension can be performed (Figure 9, $C$ and $D$ ). The free edges of the raphe are then fixed to the aortic wall at the level of the STJ to create a functional commissure, in addition to a VAJ annuloplasty. In another configuration, the raphe insertion does not reach the STJ and the fusion is fibrotic and thickened. The cranial half/third of the commissure therefore needs to be reconstructed with a pericardial patch, which extends the adjacent leaflet to the top of the commissure (Figure 9, $G$ and $H$ ).
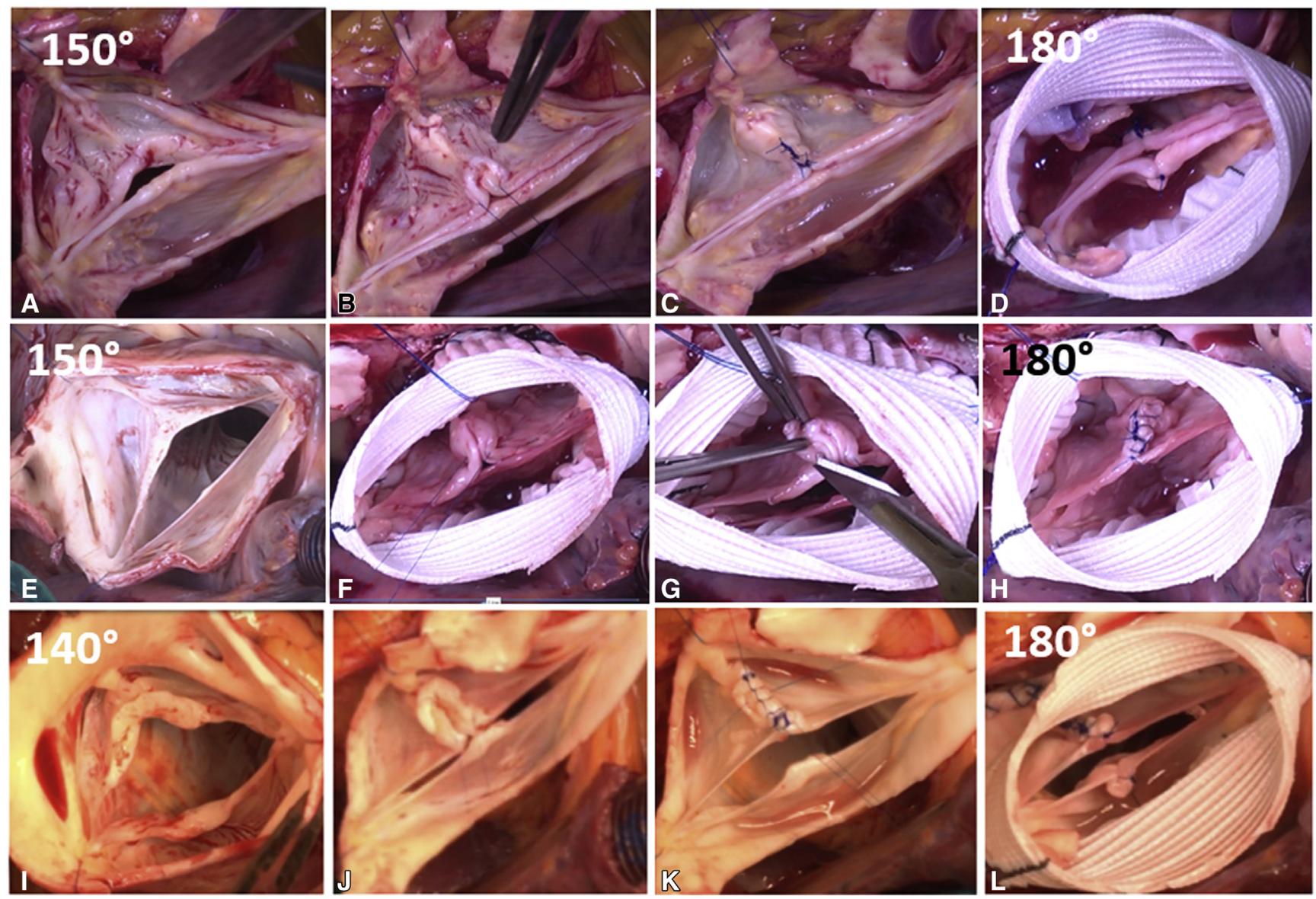

FIGURE 8. Asymmetric phenotype. (A-D) A, One hundred fifty-degree bicuspid aortic valve (BAV) with fusion right/left-cusp. B, Central plication with raphe thinning. C, Direct closure of unfused segment of fused cusp. D, One hundred eighty-degree reimplantation technique with plication of the nonfused cusp. (E-H) E, One hundred fifty-degree BAV with fusion of right/left cusps. F and G, Raphe thinning with direct closure. H, One hundred eighty-degree reimplantation technique. (I-L) I, One hundred forty-degree BAV with fusion of right/left-cusps. J, Central plication with raphe thinning. K, Direct closure of unfused segment of fused cusp. L, One hundred eighty-degree reimplantation technique with plication of the nonfused cusp. 

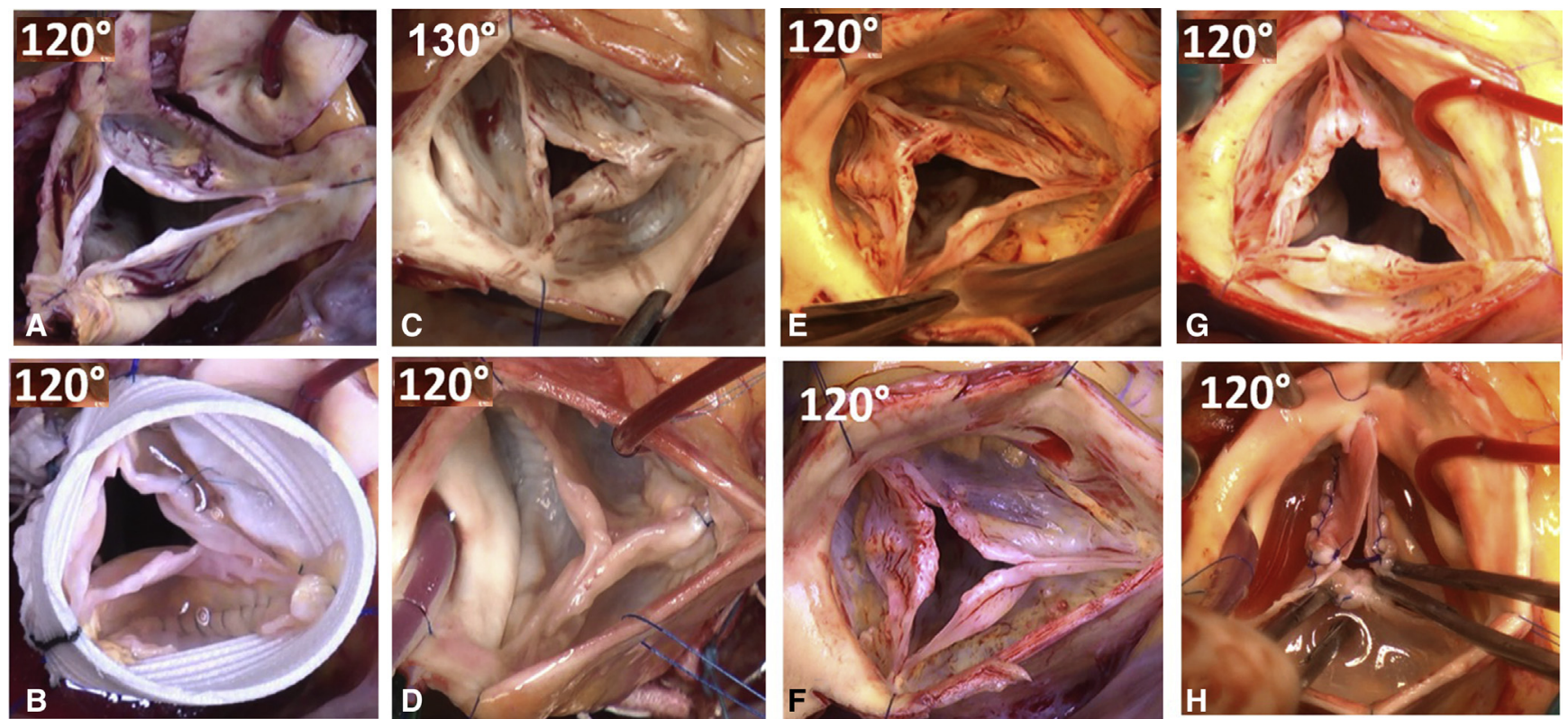

FIGURE 9. Very asymmetric phenotype requires a very tailored approach. In general, the $120^{\circ}$ configuration is kept, and a new functional commissure is created by different techniques. A and B, Type fruste with commissurotomy, right coronary cusp central plication, and $120^{\circ}$ reimplantation. C and D, Commissure resuspension. E and F, Commissurotomy and leaflet thinning. G and H, Commissure reconstruction with butterfly pericardial patch.

Another type of very asymmetric BAV are the fenestrated or chordal raphe types. These valves appear like TAV on echocardiography, and regurgitation seems to originate from a right cusp prolapse. These BAV are characterized by a fenestrated raphe, a chord (single or double) that joins the free edge of the raphe to the STJ. Sometimes, when this cord ruptures it may induce severe prolapse of the conjoined cusp. The valves are generally approached by dividing the chord(s) first (Figure 10). In this phenotype, the raphe fusion is usually longer than expected for this valve
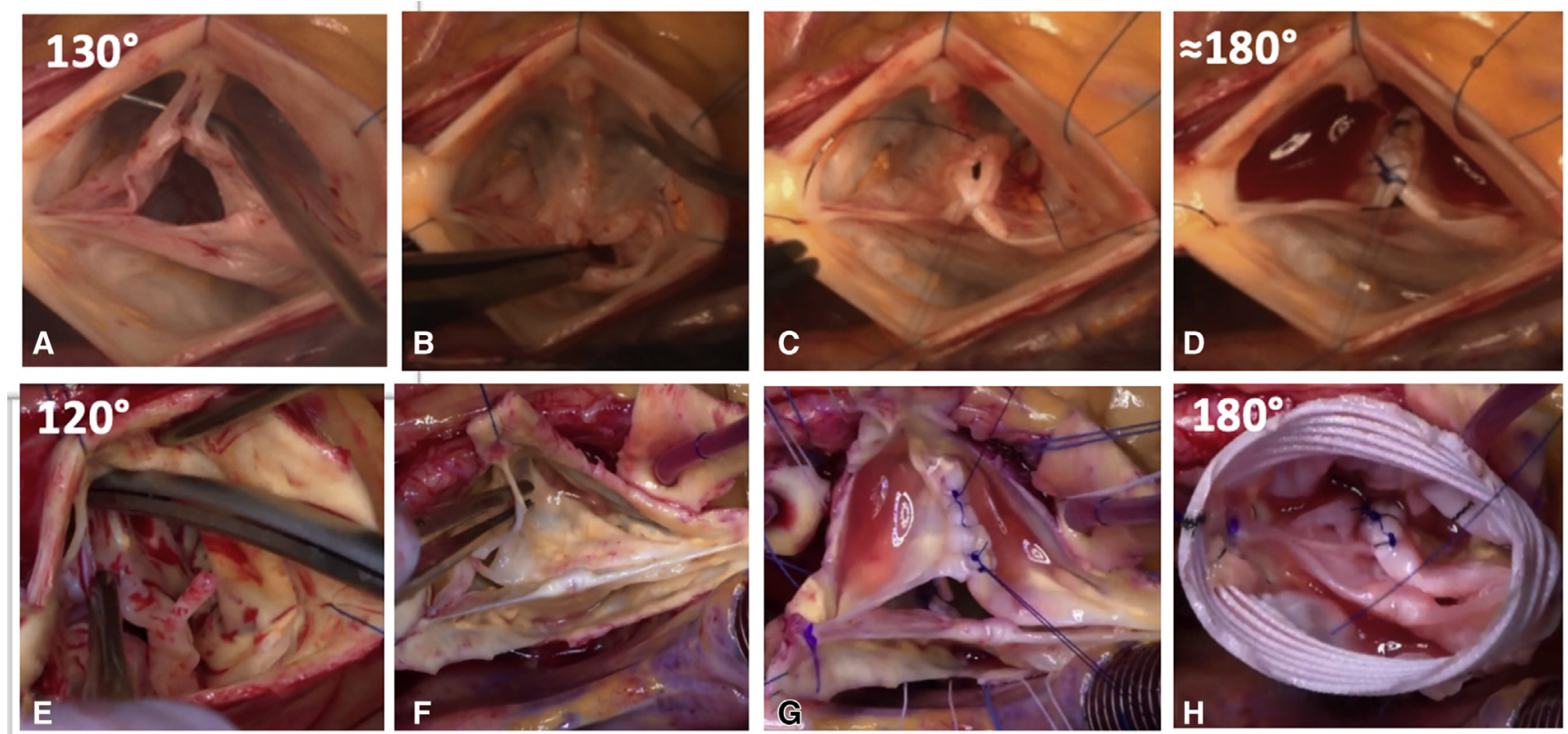

FIGURE 10. Very asymmetric fenestrated chord type. A through D, Cord resection, raphe direct closure. E through $\mathrm{H}$, Cord resection, raphe direct closure, and $180^{\circ}$ reimplantation technique. 


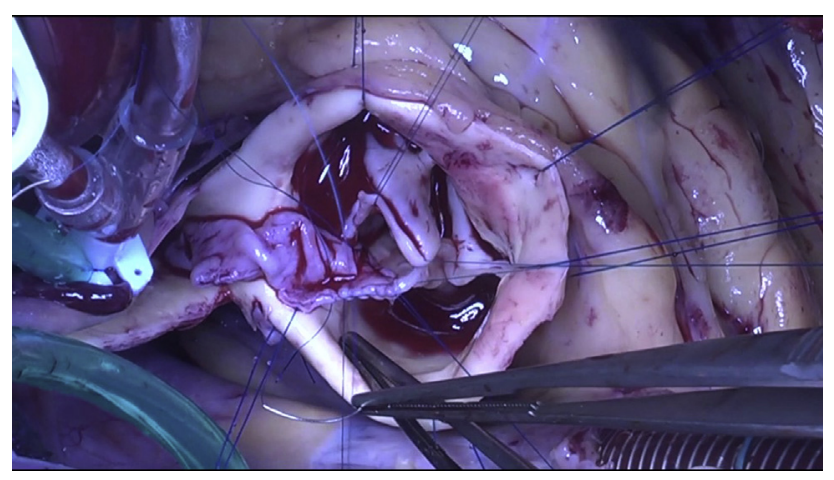

VIDEO 2. Bicuspid aortic valve repair: Very asymmetric phenotype. Butterfly pericardial patch repair, raphe shaving, and external ring annuloplasty. Video available at: https://www.jtcvs.org/article/S2666-2507(21) 00106-1/fulltext.

geometry, and the valve is therefore repaired like an asymmetric BAV with direct closure of the unfused portion of the raphe and annuloplasty $\left(180^{\circ}\right.$ reimplantation or external ring).

\section{SPECIAL CONSIDERATIONS}

\section{Leaflet Fenestrations}

A leaflet fenestration in and of itself, does not constitute a contraindication to valve preservation. If they are small, and do not add to the mechanism of AR, they are simply left alone. Large fenestrations, which are unruptured but contribute to the mechanism of AR, can be closed with a pericardial patch to plug the fenestration orifice.

If the fenestration is ruptured, then valve replacement may be indicated, unless the fenestration can be repaired via a small pericardial patch or primary closure at the level of the commissures (Video 2).

\section{Thickened Leaflets}

Excessive leaflet thickness, which limits leaflet mobility and pliability, generally requires cusp shaving (Video 3).

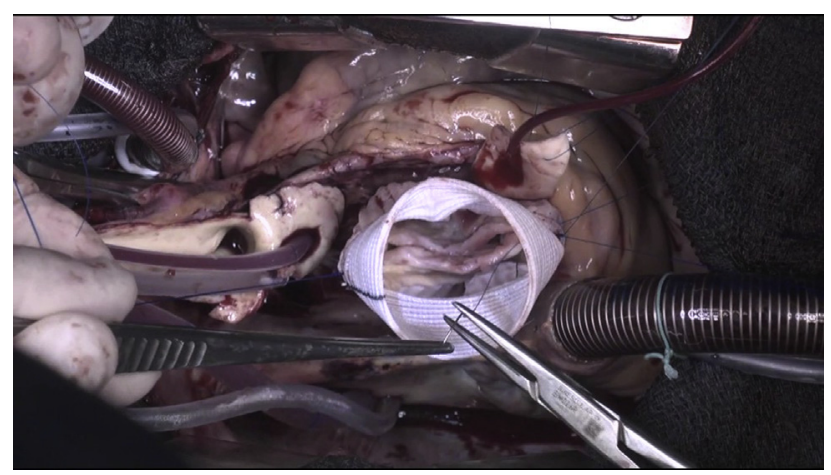

VIDEO 3. Bicuspid aortic valve repair: Asymmetric phenotype. $180^{\circ}$ reimplantation technique. Video available at: https://www.jtcvs.org/article/ S2666-2507(21)00106-1/fulltext.
This aids in achieving thinner leaflets, which also improves an existing transvalvular gradient.

\section{Raphe Excision and Repair}

In the past, we used to aggressively excise thickened raphe tissues. However, nowadays we limit resection to shaving thickened areas only, and plicate or directly close the unfused portion of the raphe, thereby also treating the fused cusp prolapse (Video 3). In cases where there is no leaflet prolapse, such as in aortic aneurysm without AR, we merely shave the raphe to provide better leaflet mobility without addressing the free margin.

\section{Leaflet Calcifications}

Mild-to-moderate leaflet calcifications, which are not transmural, can be carefully resected while paying close attention to not perforate the leaflets. However, excessive or transmural calcifications are beyond repair, and will likely require a valve replacement.

\section{COMMENTS}

In BAV with $\mathrm{AR}$, the culprit lesion for $\mathrm{AR}$ is almost exclusively a prolapse of the fused cusp. The goal of BAV repair is to achieve a competent valve with a coaptation height (effective height) of $9-10 \mathrm{~mm}$ with good mobility of both cusps. If these goals are met, a competent valve without a transvalvular gradient can be achieved.

To understand how to repair a BAV, it is important to realize that there are different phenotypes that require different approaches. It is also important to understand that to achieve a durable repair, the surgeon not only has to address the leaflets, but also stabilize the aortic annulus. Moreover, because the majority of BAVs are defined by asymmetry of the FAA and valve leaflets, it is important to create symmetry at every level, so a competent valve is once again established. This can be achieved by creating symmetric leaflets and a symmetric FAA. One tool to accomplish this is our $180^{\circ}$ reimplantation technique.

\section{Conflict of Interest Statement}

The authors reported no conflicts of interest.

The Journal policy requires editors and reviewers to disclose conflicts of interest and to decline handling or reviewing manuscripts for which they may have a conflict of interest. The editors and reviewers of this article have no conflicts of interest.

\section{References}

1. de Meester C, Pasquet A, Gerber BL, Vancraeynest D, Noirhomme P, El Khoury G, et al. Valve repair improves the outcome of surgery for chronic severe aortic regurgitation: a propensity score analysis. J Thorac Cardiovasc Surg. 2014;148:1913-20

2. Arabkhani B, Mookhoek A, Di Centa I, Lansac E, Bekkers JA, De Lind Van Wijngaarden R, et al. Reported outcome after valve-sparing aortic root replacement for aortic root aneurysm: a systematic review and meta-analysis. Ann Thorac Surg. 2015;100:1126-31. 
3. Aicher D, Holz A, Feldner S, Kollner V, Schafers HJ. Quality of life after aortic valve surgery: replacement versus reconstruction. J Thorac Cardiovasc Surg. 2011;142:e19-24.

4. Mookhoek A, Korteland NM, Arabkhani B, Di Centa I, Lansac E, Bekkers JA, et al. Bentall procedure: a systematic review and meta-analysis. Ann Thorac Surg. 2016;101:1684-9.

5. Wong CHM, Chan JSK, Sanli D, Rahimli R, Harky A. Aortic valve repair or replacement in patients with aortic regurgitation: a systematic review and meta-analysis. J Card Surg. 2019;34:377-84.

6. Chaliki HP, Mohty D, Avierinos JF, Scott CG, Schaff HV, Tajik AJ, et al. Outcomes after aortic valve replacement in patients with severe aortic regurgitation and markedly reduced left ventricular function. Circulation. 2002;106:2687-93.

7. El Khoury G, Glineur D, Rubay J, Verhelst R, d'Acoz Yd, Poncelet A, et al. Functional classification of aortic root/valve abnormalities and their correlation with etiologies and surgical procedures. Curr Opin Cardiol. 2005;20: 115-21.

8. Sabet HY, Edwards WD, Tazelaar HD, Daly RC. Congenitally bicuspid aortic valves: a surgical pathology study of 542 cases (1991 through 1996) and a literature review of 2,715 additional cases. Mayo Clin Proc. 1999;74:14-26.

9. Sievers HH, Schmidtke C. A classification system for the bicuspid aortic valve from 304 surgical specimens. J Thorac Cardiovasc Surg. 2007;133: 1226-33.

10. Schaefer BM, Lewin MB, Stout KK, Gill E, Prueitt A, Byers PH, et al. The bicuspid aortic valve: an integrated phenotypic classification of leaflet morphology and aortic root shape. Heart. 2008;94:1634-8.

11. Kang JW, Song HG, Yang DH, Baek S, Kim DH, Song JM, et al. Association between bicuspid aortic valve phenotype and patterns of valvular dysfunction and bicuspid aortopathy: comprehensive evaluation using MDCT and echocardiography. JACC Cardiovasc Imaging. 2013;6:150-61.

12. Aicher D, Kunihara T, Abou Issa O, Brittner B, Graber S, Schafers HJ. Valve configuration determines long-term results after repair of the bicuspid aortic valve. Circulation. 2011;123:178-85.

13. de Kerchove L, Mastrobuoni S, Froede L, Tamer S, Boodhwani M, van Dyck M, et al. Variability of repairable bicuspid aortic valve phenotypes: towards an anatomical and repair-oriented classification. Eur J Cardiothorac Surg. 2019; 56:351-9.

14. Schafers HJ, Schmied W, Marom G, Aicher D. Cusp height in aortic valves. J Thorac Cardiovasc Surg. 2013;146:269-74.

15. Schneider U, Feldner SK, Hofmann C, Schöpe J, Wagenpfeil S, Giebels C, et al. Two decades of experience with root remodeling and valve repair for bicuspid aortic valves. J Thorac Cardiovasc Surg. 2017;153:S65-71.

16. Schneider U, Hofmann C, Aicher D, Takahashi H, Miura Y, Schafers HJ. Suture annuloplasty significantly improves the durability of bicuspid aortic valve repair. Ann Thorac Surg. 2017;103:504-10.
17. Al-Atassi T, Hynes M, Sohmer B, Lam BK, Mesana T, Boodhwani M. Aortic root geometry in bicuspid aortic insufficiency versus stenosis: implications for valve repair. Eur J Cardiothorac Surg. 2015;47:e151-4.

18. Lansac E, Di Centa I, Sleilaty G, Lejeune S, Berrebi A, Zacek P, et al. Remodeling root repair with an external aortic ring annuloplasty. J Thorac Cardiovasc Surg. 2017; 153:1033-42.

19. Tamer S, Mastrobuoni S, van Dyck M, Navarra E, Bollen X, Poncelet A, et al. Free margin length and geometric height in aortic root dilatation and leaflet prolapse: implications for aortic valve repair surgery. Eur J Cardiothorac Surg. 2020;57:124-32.

20. Froede L, Schafers S, Wagenpfeil G, Raddatz A, Hoffmann K, Schafers HJ. Simplified determination of commissural orientation in bicuspid aortic valves. Eur J Cardiothorac Surg. 2020;58:1153-60.

21. Sperling JS, Lubat E. Forme fruste or 'Incomplete' bicuspid aortic valves with very small raphes: the prevalence of bicuspid valve and its significance may be underestimated. Int J Cardiol. 2015;184:1-5.

22. Boodhwani M, de Kerchove L, Glineur D, Rubay J, Vanoverschelde JL, Noirhomme P, et al. Repair of regurgitant bicuspid aortic valves: a systematic approach. J Thorac Cardiovasc Surg. 2010;140:276-84.e271.

23. Lansac E, de Kerchove L. Aortic valve repair techniques: state of the art. Eur J Cardiothorac Surg. 2018;53:1101-7.

24. Schneider U, Schmied W, Aicher D, Giebels C, Winter L, Schafers HJ. Sinus plication to improve valve configuration in bicuspid aortic valve repair-early results. Ann Thorac Surg. 2017;103:580-5.

25. de Kerchove L, Boodhwani M, Glineur D, Vandyck M, Vanoverschelde JL, Noirhomme P, et al. Valve sparing-root replacement with the reimplantation technique to increase the durability of bicuspid aortic valve repair. J Thorac Cardiovasc Surg. 2011;142:1430-8.

26. Kunihara T, Aicher D, Rodionycheva S, Groesdonk HV, Langer F, Sata F, et al. Preoperative aortic root geometry and postoperative cusp configuration primarily determine long-term outcome after valve-preserving aortic root repair. J Thorac Cardiovasc Surg. 2012;143:1389-95.

27. Lansac E, Di Centa I, Sleilaty G, Lejeune S, Khelil N, Berrebi A, et al. Long-term results of external aortic ring annuloplasty for aortic valve repair. Eur J Cardiothorac Surg. 2016;50:350-60.

28. Aphram G, Tamer S, Mastrobuoni S, El Khoury G, de Kerchove L. Valve sparing root replacement: reimplantation of the aortic valve. Ann Cardiothorac Surg. 2019;8:415-7.

Key Words: bicuspid aortic valve, aortic valve repair, valve-sparing reimplantation, bicuspid aortic valve classification 